Revista de Psicología Vol. 36 (2), 2018 (ISSN 0254-9247)

\title{
Relación familia-escuela y síndrome de Down: perspectivas de padres $y$ profesores
}

\author{
Nara Liana Pereira-Silva ${ }^{1}$, Vanessa Célia de Souza Rabelo ${ }^{2}$, \\ Cristina Fuentes Mejía ${ }^{3}$ \\ Universidade Federal de Juiz de Fora, Brasil
}

\begin{abstract}
Se investigó la relación entre familias con hijo con Síndrome de Down (SD) y la escuela (F-E) desde la perspectiva de familias y docentes de escuelas públicas en una ciudad del estado de Minas Gerais en Brasil. Fueron utilizados dos instrumentos para obtener información: entrevistas semiestructuradas y checklist para la caracterización de la rutina compartida y relación entre F-E. Para los progenitores la relación F-E se da en la estructura padresestudiante mientras que para las profesoras la relación F-E se produce mediante la estructura padres-profesores. Sin embargo, en los datos obtenidos en las entrevistas los progenitores señalan la relación F-E como fundamental para favorecer el desarrollo de habilidades de sus hijos con SD. Las profesoras consideran importante la relación F-E porque favorece el proceso de escolarización de niños con SD o Discapacidad Intelectual y añaden otros desafíos de constituir una escuela con enfoque inclusivo.

Palabras clave: relación familia-escuela, discapacidad intelectual, síndrome de Down, psicología del desarrollo, inclusión.
\end{abstract}

\section{Family-school relationship and Down syndrome: perspectives of parents and teachers}

This research explores the relationship between families with a son having Down syndrome (DS) and the school (F-S) from the point of view of the families and public school teachers in a city of Minas Gerais, Brazil. Two instruments were used: semi-structured interviews and a Checklist to characterize the daily shared routine and the relationship between F-S. For parents, the F-S link is evidenced in the parents-students relationship, while for teachers the F-S link is evidence in the parents-teachers relationship. In the interviews, parents indicate that the F-S relationship is fundamental to foster the development of skills for their

1 Doctora en Psicología. Docente del Departamento y Programa de Posgraduación en Psicología de la UFJF. Dirección postal: Rua José Lourenço Kelmer, código postal: 36036900 - Juiz de Fora, Minas Gerais, Brasil. Contacto: naraliana.silva@ufjf.edu.br.

2 Magíster en Psicología. Dirección postal: Rua José Lourenço Kelmer, código postal: 36036900 - Juiz de Fora, Minas Gerais, Brasil. Contacto: eusouvan@gmail.com.

3 Doctora en Psicología. Dirección postal: Rua José Lourenço Kelmer, código postal: $36036-$ 900 - Juiz de Fora, Minas Gerais, Brasil. Contacto: krisfmejia16@hotmail.com. 
children. Meanwhile, teachers consider the F-S relationship significant because it favors the schooling process for children with DS or intellectual disabilities, also adding challenges to establish schools with an inclusive approach.

Keywords: family-school relationship, intellectual disability, Down Syndrome, developmental psychology, inclusion.

\section{Relação família-escola e síndrome de Down: perspectivas de pais e professores}

Investigou-se a relação entre famílias com filho com síndrome de Down (SD) e a escola (F-E), desde a perspectiva de famílias e professores de escolas públicas, em uma cidade do estado de Minas Gerais, Brasil. Foram utilizados dois instrumentos: entrevistas semiestruturadas e checklist para caracterizar a rotina compartilhada e a relação família-escola. Para os progenitores, a relaçáo F-E acontece na estrutura pais-alunos, enquanto que para as professoras a relação F-E é desenvolvida mediante a estrutura pais-professores. Porém, os dados obtidos nas entrevistas revelaram que os progenitores destacam a relaçáo F-E como fundamental para favorecer o desenvolvimento de habilidades dos seus filhos com SD. As professoras consideram importante a relação F-E, uma vez que esta favorece o processo de escolarizaçáo de crianças com SD ou deficiência intelectual; e acrescentam outros desafios na construçáo da escola com enfoque inclusivo.

Palavras-chave: relação família-escola, deficiência intelectual, síndrome de Down, Psicologia do desenvolvimento, inclusão.

\section{Relation famille-école et syndrome de Down: perspectives des parents et des enseignants} La relation entre les familles avec enfants atteints du syndrome de Down (SD) et l'école (F-E) du point de vue des familles et des enseignants des écoles publiques dans une ville de l'État de Minas Gerais au Brésil a été étudiée. Deux instruments ont été utilisés pour obtenir des informations: des entretiens semi-structuréeset une liste de contrôle pour la caractérisation de la routine partagée et de la relation entre F-E. Pour les parents, la relation F-E se produit dans la structure parent-élève, alors que pour les enseignants, la relation F-E est produite par la structure parent-enseignant. Cependant, dans les données obtenues lors des entretiens, les parents soulignent que la relation F-E est fondamentale pour favoriser le développement des compétences de leurs enfants avec SD. Les enseignants considèrent que la relation F-E est importante parce qu'ils favorisent le processus de scolarisation des enfants atteints de SD ou de déficience intellectuelle et d'autres défis pour constituer une école avec une approche inclusive.

Mots clés: relation famille-école, déficience intellectuelle, le syndrome de Down, psychologie du développement, inclusion. 
A partir del enfoque de desarrollo humano en psicología, se considera relevante investigar la relación construida entre el sistema familiar y el escolar (F-E) (Dessen \& Polonia, 2014; Dusi, 2012; Polonia \& Dessen, 2011; Resende \& Silva, 2016). Este vínculo permite al estudiante afrontar conflictos y generar habilidades para la resolución de problemas (Dessen \& Polonia, 2014; Dusi, 2012; Polonia \& Dessen, 2011; Varani \& Silva, 2010). Acciones conjuntas y saludables entre F-E contribuyen en los procesos de aprendizaje de los estudiantes (Powel, Son, File \& San Juan, 2010; Whitaker, Graham, Severtson, Furr-Holden \& Latimer, 2012). En el mismo sentido, se indica que la participación de progenitores en actividades convocadas por la escuela influirá positivamente en el rendimiento académico de sus hijos (Llevot \& Bernad, 2015; Sánchez \& Valdés, 2011). Al ser considerados como contextos fundamentales en el desarrollo infantil, la relación entre los dos debe destacarse por la comunicación y colaboración constantes (Junges, 2015; Marcondes \& Sigolo, 2012; Petrucci, Borsa \& Koller, 2016; Resende \& Silva, 2016). La relación F-E no solo beneficia la esfera cognitiva, sino también son impactados positivamente procesos afectivos y sociales (Dessen \& Polonia, 2014).

Se identificó un aumento significativo en estudios que investigan la relación F-E (Junges, 2015; Oliveira \& Marinho-Araújo, 2010; Picanço, 2012; Powel et al., 2010; Resende \& Silva, 2016; Saraiva \& Wagner, 2013; Sousa \& Pereira, 2014; Whitaker et al., 2012). Aunque la literatura académica señala aspectos positivos en la relación, son indicados también posibles conflictos (Marcondes \& Sigolo, 2012; Saraiva \& Wagner, 2013). Por ejemplo, el estudio de Marques (1996) efectuado con una muestra de escuelas en cinco países, encontró que la relación F-E se caracteriza por una serie de obstáculos: formas negativas de comunicación, atribuir a los padres la responsabilidad directa del 
fracaso escolar de sus hijos, enfatizar constantemente en problemas y aspectos negativos de la escuela.

Por lo tanto, es fundamental investigar los mecanismos que posibilitan este vínculo, así como el contexto donde se construye. Al respecto, el estudio de Marcondes y Sigolo (2012) identificó que la relación F-E se produce mediante el intercambio de mensajes, en los encuentros entre acudientes y docentes y en las reuniones de padres de familia en horarios establecidos por la escuela. Los profesores perciben como oportunas las reuniones con los padres para discutir acerca del rendimiento académico y comportamental del estudiante mientras que los padres perciben la información recibida en estas reuniones como negativa, superficial y como un motivo para distanciarse del sistema escolar. Este estudio también encontró que la forma más frecuente de vínculo según la perspectiva de progenitores es cuando supervisan las tareas de sus hijos. Sin embargo, la investigación sugiere mayor participación de los progenitores para que se generen otros canales de interacción con la escuela (Marcondes \& Sigolo, 2012).

\section{Relación familia - escuela: estudiantes con Discapacidad Intelectual o Síndrome de Down}

Pocas son las investigaciones interesadas en la relación entre escuela y familias de estudiantes con Discapacidad Intelectual (DI), siendo aún más escasos los estudios que tratan específicamente de estudiantes con Síndrome de Down (SD) (Rabelo, 2013). Se considera que el vínculo entre familias de estudiantes con algún tipo de limitación y el sistema escolar presenta características propias, no solo por la singularidad de la dinámica de una familia con hijos con SD (Pereira-Silva, Oliveira \& Rooke, 2015; Rabelo, 2013), sino también, por los diversos aspectos involucrados en una educación bajo la perspectiva de la inclusión (Garcia, 2013; Pletsch \& Glat, 2012; Zanato \& Gimenez, 2017).

La revisión de literatura de Luiz, Bortoli, Floria-Santos y Nascimento (2008) analizó estudios efectuados desde 1994 hasta 2007, concluyendo que el papel desempeńado por los progenitores y la buena relación que construyen con la escuela, favorecen procesos de inclu- 
sión; agregando que los profesionales de la escuela deben compartir con la familia los cuidados propios que requieren los estudiantes con SD. El estudio recomienda crear ambientes estructurados y adaptados a las particularidades de cada estudiante, invertir en la capacitación de profesionales, preparar a los demás estudiantes para recibir a otros con necesidades educativas especiales (NEE). Según los autores, es competencia del profesor identificar, planear y adaptar estrategias que faciliten al estudiante con NEE acceso al currículo, fomentar su independencia, así como mediar en las relaciones entre estudiantes.

Silva y Mendes (2008) realizaron una investigación con profesionales y padres de nińos con discapacidad, el estudio tuvo como objetivo describir comportamientos que favorezcan una alianza, caracterizada por la colaboración entre F-E, distinguida por una serie de aspectos y valores como el respeto, confianza, participación, sinceridad, seriedad, imparcialidad y comunicación. Sin embargo, no se identificó en los relatos de los participantes la categoría de empoderamiento, esto indica que tanto profesionales como familias no se perciben en igualdad de condiciones y, por el contrario, son trazadas diferencias acentuadas en los papeles que cada uno de ellos desempeńa. Estos roles asumidos deben ser complementarios e igualmente importantes. Los resultados señalan la necesidad de redefinir roles en esta alianza en pro de una adecuada aproximación entre F-E que favorezca a los estudiantes con DI.

El análisis de Prata (2009) reveló, a partir de relatos de profesores, un discurso reiterativo acerca de la falta de colaboración por parte de las familias de estudiantes con DI, además de señalar el bajo impacto del vínculo escuela-comunidad; situaciones que interfieren y no contribuyen en el proceso de inclusión. Resultados de este estudio apuntan a un déficit en la inversión para la capacitación de profesionales, aspecto que también fue identificado en la investigación de Luiz et al. (2008).

El estudio de Christovam y Cia (2016) con familias de estudiantes con SD o DI y otras NEE describió cómo 60 padres y 54 profesores construyen la relación F-E, para tal fin, fueron examinadas estrategias, frecuencia, actividades y situaciones que promueven la relación. El interés de los padres frente al desempeño académico de sus hijos fue 
identificado en la frecuencia con que los padres asisten a la escuela, los progenitores tuvieron siete opciones de respuesta a saber: todos los días; no asiste a la escuela del hijo sin ser convocado; una vez por semana; dos o tres veces por semana; dos veces por mes; una vez por bimestre (de los cuatro establecidos durante el año escolar) y una vez por mes. El porcentaje mayor de $33.3 \%$ afirmó no acudir a la escuela sin ser convocado, seguido del $20 \%$ que afirmó asistir a la escuela todos los días. Este último dato fue contrastado con las respuestas de los docentes, según ellos, intereses relacionados al comportamiento, desarrollo y aprendizaje de los estudiantes, son los mismos tanto en padres de estudiantes con NEE como de aquellos con desarrollo típico. Frente a este dato, el estudio señala que puede ser interpretado de tres posibles maneras. La primera de ellas indicando la falta de interés por parte de los progenitores hacia el proceso educativo de su hijo. La segunda, corresponde a un probable desconocimiento de los padres acerca de la importancia de su participación en la escuela; y una tercera interpretación indica que todos los padres con o sin hijos con necesidades educativas especiales, participan con la misma frecuencia en las actividades académicas de sus hijos.

Christovam y Cia (2016) identificaron que las estrategias de comunicación adoptadas entre padres y profesores incluyen notas en agendas (profesores 85,1\%; padres 30\%) y reuniones de padres (profesores $81,1 \%$; padres $71,67 \%$ ). Se identificaron otros mecanismos de comunicación tales como: encuentros informales, contacto telefónico y reuniones individuales. Estas estrategias de colaboración también fueron halladas en el estudio de Marcondes y Sigolo (2012) con padres de estudiantes con bajo desempeño académico.

Es importante resaltar que, en el contexto brasileño, antes de llegar a difundirse la idea de inclusión en la escuela regular, la escuela especial trabajaba concomitantemente atendiendo estudiantes con un tipo de interferencia en su desarrollo. Al respecto, Luiz y Nascimento (2012) señalan que familias de estudiantes con SD experimentan sentimientos frente a la transición entre la escuela especial y la regular tales como inseguridad, tensión y preocupación por la pérdida de servicios 
terapéuticos ofrecidos por la institución especial. El estudio de Silva (2007) investigó los factores que llevaron a tres estudiantes con DI a volver a un tipo de educación especial luego de haber estado llevando una regular, datos que fueron obtenidos por medio de los relatos de familias, entrevistas y evaluación de profesionales en los dos tipos de escuelas. Aspectos señalados por los participantes indican obstáculos en el contexto educativo para hacer efectiva la inclusión, aunque los profesores están a favor de la propuesta inclusiva manifiestan dudas frente a las acciones que deberían promover para el desarrollo cognitivo de ese grupo de estudiantes. Otras limitaciones son el número elevado de estudiantes en el salón, la carencia de recursos y la falta de formación y capacitación de los profesores.

Los trabajos académicos encontrados en las bases de datos que tratan la especificidad de la relación entre F-E con estudiantes con $\mathrm{SD}$ son escasos. Ante este panorama, el presente artículo tiene como objetivo central caracterizar la relación construida entre familias de estudiantes con SD y la escuela regular con enfoque inclusivo en una ciudad del estado de Minas Gerais en Brasil.

\section{Método}

\section{Participantes}

Los participantes fueron cuatro familias que serán identificadas como F1, F2, F3 y F4 y cuatro profesoras P1, P2, P3 y P4. Las familias estaban compuestas por padre, madre y un hijo diagnosticado con SD, para un total de cuatro niños: dos del sexo masculino, de 9 años cada uno y dos niñas de 8 y 9 años respectivamente; quienes se encontraban cursando el $3^{\circ}$ año de enseńanza fundamental en escuelas de la red municipal de una ciudad en el estado de Minas Gerais en Brasil.

La media de edad de los progenitores fue de 45 ańos. El grado de escolaridad de las madres varió entre enseńanza media completa (F1 y F3) hasta enseñanza fundamental no finalizada (F2 y F4). Los padres reportaron enseńanza media completa $(\mathrm{F} 3)$, enseñanza media incom- 
pleta (F2) y enseñanza fundamental incompleta (F1 y F4). El promedio de la renta familiar fue de 2.93 salarios mínimos brasileros. En el momento de la recolección de los datos el salario mínimo se encontraba en 678.00 reales (aproximadamente 208.44 USD). En relación con la ocupación laboral de los progenitores, dos madres eran auxiliares de servicios generales y dos amas de casa. Tres padres trabajaban como profesionales independientes y uno trabajaba como portero.

El promedio de edad de las profesoras fue de 45 años con una media de 18 años de trabajo como docentes. En lo referente a la formación académica dos profesoras eran pedagogas (P1, P3), una profesora graduada como filósofa y psicóloga con maestría en educación y especialización en trastornos del comportamiento (P2) y una profesora con licenciatura y especialización en psicopedagogía, capacitada en el curso de Atendimiento Educativo Especializado (AEE) ofrecido por la Secretaria Municipal de Educación (P4).

\section{Medición}

Para lograr identificar la relación entre escuela y familias de estudiantes con SD fue aplicado el checklist para la caracterización de la rutina compartida y relación entre F-E: versión para padres y profesores, además de ser realizadas entrevistas tanto con progenitores como con profesoras. Las dos versiones del checklist fueron elaboradas por Dessen y Polonia en el marco del estudio titulado: As relaçóes familiaescola: o que diretores, professores, pais e alunos pensam? Esta investigación fue realizada con profesores y familias de estudiantes de enseñanza básica en escuelas de Brasilia, Brasil, con un total de 391 participantes. En esta investigación fueron realizados cálculos estadísticos para la validación del instrumento, encontrándose un valor de Alfa de Cronbach de .71 indicando una magnitud de confiabilidad alta del instrumento (Polonia, 2005). Posterior a este primer estudio, donde el checklist fue construido, otras investigaciones realizadas en Brasil han utilizado el instrumento (Gualda, 2015; Rabelo, 2013).

Este checklist tiene como énfasis obtener información acerca de las acciones o actividades compartidas entre padres y profesores, llamadas 
de áreas o dimensiones académicas y no académicas. La dimensión académica se relaciona con el aprendizaje formal del estudiante mientras que la dimensión o área no académica se refiere a otro tipo de actividades no necesariamente de aprendizaje, que ocurren en la escuela como, por ejemplo, las actividades culturales o simplemente aquellas denominadas de extraescolares. Las dos dimensiones se componen de categorías relacionadas con: orientación, participación, información y evaluación. La versión para profesores contiene 46 preguntas mientras que el de la familia tiene 55. Las preguntas están formuladas para que los participantes respondan sí o no (Dessen \& Polonia, 2011).

La orientación tiene que ver con estrategias utilizadas por algún miembro de la escuela para suministrar información que ayude a mejorar el desempeño de otra persona, podrán encontrarse ítems como el siguiente: ¿usted como profesor recibe instrucciones por parte de la dirección o del equipo de apoyo pedagógico para resolver dificultades de aprendizaje de los estudiantes? (dimensión académica). La participación se refiere al grado de adherencia que tienen los participantes del sistema escolar en una actividad, si lo hacen de forma voluntaria o no y si se asume un rol de colaboración. Se encuentran preguntas como esta: jen su condición de padre/madre/responsable usted ofrece ayuda al profesor para planear actividades socioculturales? (dimensión no académica).

La información se refiere a la circulación de hechos/eventos/ actividades a través de notas, boletines y otros canales de comunicación, se encuentran cuestiones como la siguiente: ‘en su condición de profesor(a) usted escribe notas que contienen información de las actividades de la semana y las envía a las familias de los estudiantes para que ellas sepan que actividades se realizan en la escuela? (dimensión no académica). La evaluación tiene que ver con la identificación y análisis de situaciones y problemas, se encuentran preguntas como esta: ¿̨usted como padre/madre/responsable conversa con el profesor sobre el desempeño del profesor en el salón de clases? (dimensión académica). De acuerdo con Dessen y Polonia (2011), el checklist además de permitir recolectar información del cotidiano escolar incluye actividades de los 
profesores y de la familia distinguiendo para cada una de estas partes estructuras diádicas, triádicas y poliádicas, de la siguiente manera:

- Profesores: díadas (profesor-padres, profesor-dirección, profesor-estudiantes, padres-estudiantes, padres-dirección); tríadas (profesor-dirección y padres) y poliádicas (profesordirección-padres y estudiantes)

- Familia: díadas (padres-profesor, padres-dirección, padres-hijo, padres-padres); tríadas (padres-profesor-dirección) y poliádicas (padres-profesor-dirección-estudiante).

Las entrevistas efectuadas a progenitores y docentes tuvieron como objetivo la obtención de datos acerca de la relación F-E bajo el marco de la escuela regular con enfoque inclusivo. De este modo, fueron planeados dos guiones de entrevistas semiestructuradas, uno para progenitores y otro para las profesoras. Los ejes de la entrevista con los progenitores fueron los siguientes: diagnóstico, desarrollo psicomotor del estudiante, perspectivas del concepto de familia, perspectivas del concepto de escuela, relación familia-escuela. Los ejes de la entrevista con las profesoras fueron los siguientes: experiencia como educador(a), consideraciones del desarrollo psicomotor y desempeño académico del estudiante; percepciones acerca de la interacción social del estudiante: en el salón de clases, en otros espacios de la escuela y con la familia, expectativas acerca del futuro del estudiante con SD y relación F-E. El promedio de duración de las entrevistas con cada uno de los participantes fue de treinta minutos.

\section{Procedimiento}

Luego de la aprobación del estudio por el Comité de Ética e Investigación con seres humanos de la Universidad Federal de Juiz de Fora bajo el $n^{\circ} 173.306$, las investigadoras entraron en contacto con las escuelas, enviando posteriormente una carta a familias con hijos con SD, como también a docentes que tenían contacto con estos estudiantes. La recolección de datos con los progenitores fue realizada en la 
residencia familiar, mediante dos visitas. Durante la primera, se solicitó firmar el Término de Consentimiento Libre y Esclarecido (TCLE), se proporcionó información adicional sobre la investigación y fue llevada a cabo la entrevista con los progenitores. En la segunda visita fue aplicado el Checklist, se sugiere que este instrumento sea aplicado a aquel progenitor o persona responsable por acompañar al estudiante en los procesos académicos; en el caso del presente estudio, fueron las madres quienes reportaron tener mayor contacto con la escuela en comparación con los padres. Con las profesoras que aceptaron participar, se realizó una única visita a la escuela para la firma del TCLE, entrevista y diligenciar el Checklist: versión profesores.

\section{Análisis de datos}

Las entrevistas fueron trascritas en su totalidad y sometidas a un análisis basado en el sistema integrado de categorías, propuesto por Dessen y Cerqueira-Silva (2011), siguiendo estos pasos: (a) selección y exploración del material, (b) agrupar temas y (c) definición y validación de categorías empíricas, en un tratamiento de los datos que complementa el modelo de análisis de contenido propuesto por Bardin (2011).

\section{Resultados}

En primer lugar, serán presentados los datos obtenidos por medio del Checklist; acto seguido, se expondrán datos en forma de narrativas producto de las entrevistas realizadas a los progenitores y profesoras.

\section{Actividades compartidas en la relación familia-escuela}

En cuanto a la descripción que la familia realiza de la relación que construye con la escuela obtenida mediante el checklist, la Tabla 1 muestra la dinámica entre las categorías de la relación familia-escuela (orientación, participación, información y evaluación) que considera el vínculo entre las estructuras (padres, profesores, directivos y estudiantes) como también entre las áreas o categorías (académica y no académica). 
Por tanto, los números que aparecen en las tablas indican la frecuencia con la que acontece la relación familia-escuela, describiendo en cual estructura, en que área y en cuales categorías la relación es construida.

La Tabla 1 evidencia que la relación F-E de la muestra investigada se establece en todas las categorías. Sin embargo, en la categoría orientación, esta se produce con mayor frecuencia especialmente entre padres-estudiantes en un contexto académico y no académico, como también entre padres-profesores en el área académica. La participación de las madres con la escuela ocurre entre ellas y los estudiantes en un contexto académico y no académico también esta categoría presenta mayores índices de ocurrencia entre padres-profesores-dirección en el área académica. El intercambio de información se da entre padres en contextos extraescolares,

\section{Tabla 1}

Caracterización de la rutina y la relación compartida entre familia-escuela, según las madres

\begin{tabular}{llcccc}
\hline \multirow{2}{*}{ Estructura } & Área/ & \multicolumn{4}{c}{ Categorías } \\
\cline { 3 - 6 } & Dimensión & $\begin{array}{c}\text { Orien- } \\
\text { tación }\end{array}$ & $\begin{array}{c}\text { Partici- } \\
\text { pación }\end{array}$ & $\begin{array}{c}\text { Infor- } \\
\text { mación }\end{array}$ & $\begin{array}{c}\text { Evalua- } \\
\text { ción }\end{array}$ \\
\hline \multirow{2}{*}{ Padres- profesor } & Académica & 2 & 0 & 2 & 0 \\
& No académica & -- & 0 & -- & - \\
\hline \multirow{2}{*}{ Padres-dirección } & Académica & -- & 0 & -- & - \\
\hline \multirow{2}{*}{ Padres-estudiante } & No académica & -- & 0 & -- & - \\
\hline \multirow{2}{*}{ Padres-padres } & Académica & 2 & 2 & -- & 2 \\
\hline Padres-profesor- & No académica & 4 & 1 & -- & 2 \\
\hline dirección & Académica & -- & -- & -- & 1 \\
\hline Padres-profesor- & No académica & -- & 0 & 3 & - \\
\hline dirección-estudiante & Académica & -- & 2 & -- & 1 \\
\hline & No académica & -- & 0 & -- & - \\
\hline
\end{tabular}

Nota. Los guiones corresponden a categorías y áreas que el instrumento no se propone medir. 
aunque se produce en la estructura padres-profesores en el área académica. La categoría de evaluación es caracterizada por la díada padres-estudiantes en el contexto académico y no académico, aunque efectuada en las estructuras padres-padres y padres-profesor-dirección en el área académica. La Tabla 2 señala los resultados de las profesoras en lo que atañe a su percepción del vínculo familia-escuela.

\section{Tabla 2}

Caracterización de la rutina compartida y relación entre familia-escuela según las profesoras

\begin{tabular}{llcccc}
\hline \multirow{2}{*}{ Estructura } & Área/ & \multicolumn{5}{c}{ Categorías } \\
\cline { 3 - 6 } & Dimensión & $\begin{array}{c}\text { Orien- } \\
\text { tación }\end{array}$ & $\begin{array}{c}\text { Partici- } \\
\text { pación }\end{array}$ & $\begin{array}{c}\text { Infor- } \\
\text { mación }\end{array}$ & $\begin{array}{c}\text { Evalua- } \\
\text { ción }\end{array}$ \\
\hline \multirow{2}{*}{ Profesor-padres } & Académica & 3 & 1 & 0 & 2 \\
& No académica & 1 & 1 & -- & -- \\
\hline \multirow{2}{*}{ Profesor-dirección } & Académica & 4 & 3 & -- & 4 \\
\hline \multirow{2}{*}{ Profesor-estudiante } & No académica & 4 & 4 & -- & -- \\
\hline Padres-estudiante & Académica & 4 & -- & 3 & 2 \\
\hline \multirow{2}{*}{ Padres-dirección } & No académica & 4 & -- & 4 & -- \\
\hline Profesor-dirección-padres & Académica & 3 & -- & -- & -- \\
\hline Profesor-dirección-padres- & Académica & -- & 1 & -- & -- \\
\hline estudiantes & Académica & -- & 1 & -- & -- \\
\hline
\end{tabular}

Nota. Los guiones corresponden a categorías y áreas que el instrumento no se propone medir.

Las profesoras consideran que la relación se establece en las cuatro categorías y dan mayor énfasis a la orientación que ocurre entre los diferentes agentes (profesor-padres, profesor-dirección, profesor-estudiante, padres-estudiante, padres-dirección) y en las dos áreas académica y no académica. Mientras que la participación se da entre las díadas 
profesor-padres, profesor-dirección en un contexto académico y no académico. Entre tanto, la participación de padres-dirección ocurre en actividades no académicas. En las estructuras profesor-dirección-padres y profesor-dirección-padres-estudiantes, quienes participan de actividades estrictamente académicas, también fue presentada ocurrencia en dicha categoría. Existe intercambio de información entre profesores y estudiantes en áreas académicas y no académicas como también entre la díada padres-dirección en aspectos no académicos. En la categoría de evaluación hubo relación entre profesor-padres, profesor-dirección y profesor-estudiante en el área académica.

\section{Perspectivas de los padres frente a la relación familia y escuela}

En los relatos de entrevistas con los progenitores se logró identificar la importancia que otorgan a la construcción de una relación con la escuela debido a que favorece el desarrollo de habilidades de sus hijos con SD. Los padres entrevistados afirmaron que la relación es fundamental porque posibilita el intercambio de información, proximidad entre miembros de la F-E, complementa el desarrollo del estudiante, se reúnen esfuerzos para la transmisión de valores y favorece el trabajo del docente. En las narrativas de los progenitores el intercambio de informaciones entre F-E hace referencia principalmente al comportamiento del estudiante en el salón de clase, el cual es observado y posteriormente comunicado a los padres de familia y que, de acuerdo con los padres, son aspectos comportamentales que deben trabajarse también en el hogar.

"A gente tá ciente do que está acontecendo na sala de aula, pra gente poder chamar atençâo em casa, mas se você nâo tá sabendo, como é que vai fazer?" [La gente está consciente de lo que está sucediendo en el aula, para que pueda llamar la atención en casa, pero si usted no sabe, ¿cómo es que va a hacer?] (Padre).

En cuanto al tema de la proximidad entre los sistemas familiaescuela se destacó la organización de actividades extraacadémicas, de esta manera los padres se ven involucrados y demuestran interés por acercarse más al mundo de la escuela. 
"é importante sim... ter mais atividades assim, que envolvesse os pais, né, uma... uma... brincadeira" [es importante sí... tener más actividades, que implique a los padres, no, una... una... broma] (Padre).

También fue relevante la característica de complementariedad en la relación F-E. Los padres de familia manifiestan que los procesos académicos en los cuales el estudiante aprende a leer y a escribir no son función exclusiva de la escuela, puesto que la familia juega un papel importante en estos procesos de alfabetización. Además, fueron identificadas posturas morales y éticas al señalar que la alianza F-E permite formar valores en el estudiante y que cada una de las partes asume roles propios en esta tarea.

"Com certeza, porque se os pais deixarem só por conta da escola, talvez não vai... ela vai aprender a ler e a escrever, mas será que ela vai ser uma pessoa melhor? Eu acho que não. Se a escola deixar só por conta dos pais, e a escola nada... também não. Eu acho que cada um tem a sua parcela, cada um tem que assumir a sua parcela ali e ir pra frente" [Por supuesto, porque si los padres la dejaran solo por cuenta de la escuela, ella tal vez no va... ella va a aprender a leer y a escribir, pero, ¿será que va a ser una persona mejor? Creo que no. Si la escuela la deja solo por cuenta de los padres, y la escuela nada... tampoco. Yo creo que cada uno tiene su propio tema, cada uno tiene que asumirlo y seguir alli e ir para adelante] (Padre).

"pela informação sobre... muita... ela (a escola) dá muita atenção às coisas, entâo ajuda... na própria, na própria educação dela mesmo, pra saber direcionar as coisas certas, as coisas erradas, né?" [por la información sobre... mucha... ella (la escuela) da mucha atención a las cosas, entonces ayuda... en la propia, en la propia educación de ella misma, para saber dirigir las cosas correctas, las cosas equivocadas, no?] (Padre).

Los progenitores señalan que la relación entre los dos sistemas favorece el trabajo docente de manera especial cuando se trata de niños con SD. Se ha puesto de manifiesto el interés en acompañar el proceso académico de sus hijos; sin embargo, se interpreta que más allá de apoyar el trabajo del docente, se trata de una exigencia por parte de los padres hacia los profesores con el fin de desarrollar actividades 
académicas que favorezcan el aprendizaje de sus hijos. Una de las madres participantes indica que ella solicita a los profesores que sean trabajados determinados temas con su hijo, como puede observarse en la narrativa presentada a continuación. De manera general fue identificado en los relatos un déficit de escenarios de aprendizaje que permitan a los estudiantes con DI el desarrollo de sus capacidades. Esto conlleva a que los progenitores no se sientan conformes con el servicio educativo. Este último aspecto es característico de los conflictos que podrían emerger en la relación F-E.

"... porque eles acabam trabalhando mais com ela, pela minha cobrança" [porque ellos terminan trabajando más con ella, con mi cuenta] (Madre).

\section{Los progenitores frente al papel que ejerce la escuela regular con un enfoque inclusivo}

Durante el análisis de la información se encontró que tanto padres y madres al referirse a la díada F-E atribuyeron una serie de papeles que la escuela asume; roles que vinculan directamente a sus hijos con SD. Fueron encontradas las siguientes caracterizaciones: escuela encargada del aprendizaje formal, explora el potencial de los niños, ofrece soporte profesional, trasmite valores, acepta y ayuda a socializar.

Frente a la escolarización de carácter formal, los padres atribuyen procesos que deben ser prioritarios en la escuela. Por ejemplo, el proceso de alfabetización y el aprendizaje de matemáticas; las narrativas enfatizan que la escuela es quien presenta mayor responsabilidad para ejercer esta tarea.

"O objetivo da escola é ensinar a ler e a escrever, e a fazer contas..." [El objetivo de la escuela es enseñar a leer y a escribir, y a hacer cuentas...] (Padre).

Sin embargo, los padres consideran que la escuela es el lugar para que los docentes generen situaciones que promuevan las capacidades de sus hijos con síndrome de Down. Los potenciales de sus hijos pueden ser aprovechados por los profesores para trabajar en el salón de clases. 
"Aproveitar a inteligência dela. Assim... trabalhar bastante com ela lá dentro" [Aprovechar la inteligencia de ella. También... trabajar bastante con ella alli adentro] (Madre).

El aspecto de soporte o apoyo profesional fue explicitado según las narrativas de los padres en dos componentes: Emocional/comportamental y aprendizaje.

a) Emocional/comportamental. Frente a determinados comportamientos del estudiante con DI, los padres relatan recibir frecuentemente quejas de conductas de su hijo en el salón y en otros espacios de la institución. Sin embargo, en las escuelas regulares y públicas brasileras existe, dentro de la planta docente, un profesor de apoyo que generalmente trabaja con los estudiantes con NEE, incluyendo en este grupo la DI. De esta manera, los padres cuentan con un profesional que apoya procesos de enseńanza y aprendizaje.

"Sempre tem uma reclamação na escola dele... todo dia tem um negócio... o A. não quer ficar na sala, o A. deitou no chão, falou que morreu $o$ avô dele... ele sempre inventa um negócio [SIC]. Mas ele faz isso, né? (...) eu achava que tinha que ter uma pessoa pra ficar com ele na sala, um professor de apoio" [Siempre tiene una queja en su escuela... cada día tiene un negocio... A. no quiere quedarse en la sala, $A$. se acostó en el suelo, contó que murió su abuelo... él siempre inventa un negocio [SIC]. Pero él lo hace, ¿no? (...) creía que tenía que tener una persona que se quedase con él en la sala, un profesor de apoyo] (Madre).

b) Aprendizaje. Este aspecto se encuentra en estrecha relación con el anteriormente descrito. Se percibe en los discursos exigencia frente a los derechos que tienen como padres de un estudiante con DI o DS cuando hacen parte de la vida escolar, dentro de los cuales se encuentran solicitar un profesor de apoyo. De acuerdo con la narración, en la medida en que un profesor brinda atención suficiente al estudiante, se contribuye para que el niño aprenda más rápido.

“... eu quero ir e quero exigir e eles vão ter que pôr uma professora com ele lá na escola... Eu creio que se der mais atenção, a tendência é aprender mais rápido" [yo quiero ir y quiero exigir y ellos van a tener que 
poner una profesora con él allá en la escuela... Yo creo que si se presta más atención, la tendencia es a aprender más rápido] (Padre).

Los padres atribuyen que a la escuela le corresponde un papel ético y moral. El estudiante estará en capacidad de aprender valores para su formación como ciudadano y así como algunos saberes que apoyan la construcción de su futuro.

"Pra ser uma cidadã, educar... formar... ela uma pessoa para o futuro mesmo. É, uma pessoa intuitiva, tem... tem força de vontade" [Para ser una ciudadana, educar.. formar... ella es una persona para el mismo futuro. Es, una persona intuitiva, tiene... tiene fuerza de voluntad] (Padre).

Los padres relataron que la aceptación social y la vinculación de sus hijos a una escuela regular fueron adecuadas.

"Ó, a aceitação dele como Down... ele foi muito bem aceito" [Oh, la aceptación de él como Down... él fue muy bien aceptado] (Padre).

Uno de los aspectos que es a menudo tema de interés de padres de estudiantes con DI o SD es la búsqueda de la escuela para que su hijo logre socializar. En este sentido, las narraciones de los padres priorizan la escuela porque permite que sus hijos convivan con el resto del grupo en una clase, comprendiendo las particularidades del resto de estudiantes. El salón de clases es visto como un espacio para la comprensión de la diversidad, además de la riqueza de este escenario para la formación del estudiante con SD.

"Mas, muito mais do que isso, a gente sabe que é o convivio em comunidade, assim... você estar dentro de sala de aula com um colega, cada um tem um pensamento sobre a mesma coisa; tem lá entre 20 e 30 alunos... sobre o mesmo assunto, cada um pensa diferente, então isso é importante pra ela" [Pero, mucho más que eso, la gente sabe qué es la convivencia en comunidad, así... usted está dentro del aula con un compañero, cada uno tiene un pensamiento sobre la misma cosa; tiene entre 20 y 30 alumnos... sobre el mismo tema, cada uno piensa diferente, entonces eso es importante para ella] (Padre). 


\section{Perspectivas de las profesoras frente al proceso de escolarización: desempeño académico de los estudiantes con $S D$}

Las profesoras llevaban entre 6 a 17 meses acompañando el proceso académico de los niños con SD dentro del salón de clases. De acuerdo con los relatos, la relación F-E es vital porque favorece el proceso de escolarización de nińos con SD. Este proceso fue considerado según el desempeño académico de los estudiantes, siendo descrito en las siguientes categorías: dificultades en el aprendizaje, falta de continuidad en el mismo, desempeño satisfactorio para algunos de ellos, aspectos comportamentales y estados de ánimo.

Las dificultades que fueron encontradas en los relatos de las profesoras hacen referencia a los procesos de lenguaje y concentración, los cuales interfieren en el desempeño de los estudiantes. De acuerdo con una de las narrativas, el proceso de alfabetización no se lleva a cabo de la mejor forma ante la dificultad que presenta este grupo de niños para hablar y expresar sus ideas.

"Não tenho como saber, porque ele não fala. Muito pouco, por exemplo, eu fazendo exercícios pra ele sobre o abecedário, eu nem cheguei no silábico ainda, né, que é "ba", "ca", "ma", pra poder marcar a formação de silabas, né? Eu nem cheguei porque eu nâo sei se ele reconhece todas as letras e a relação número quantidade entendeu? Porque por ele não falar ele não dá o feedback" [No tengo cómo saber, porque no habla. Avanza muy poco, por ejemplo, yo haciendo ejercicios para él sobre el abecedario, ni siquiera llegué al silábico, que es "ba", "ca", "ma", para poder marcar la formación de sílabas, ¿no? Yo no llegué porque yo no sé si él reconoce todas las letras y la relación número cantidad ¿entendió? Porque por no hablar él no da la retroalimentación] (P2).

En cuanto al tema de concentración de los estudiantes con SD, en la narrativa se manifiesta que se deben crear varias actividades para ellos y tener en cuenta algunas situaciones biológicas como el 'cansancio' que interfiere con la concentración en las actividades.

"Só que a concentração dela é pouca, então as atividades dela têm que ser variadas, vocêtem que trocar sempre, e tem hora que ela se apresenta, 
assim, cansada, ela quer deitar um pouquinho a cabeça [...]. Só que nós vimos que existe uma dificuldade muito grande nela de concentração" [Solo que su concentración es poca, entonces sus actividades tienen que ser variadas, uno tiene que cambiar siempre, y tiene la hora en que ella se presenta, así, cansada, ella quiere echar un poquito la cabeza [...]. Solo que hemos visto que ella tiene una dificultad muy grande de concentración] (P4).

"A questão de concentração em atividades, leitura; nós temos o cantinho da leitura lá, uma caixa de livros, que uma determinada hora ela quer; ela pega os livros, ela conta a história dos livros, como se estivesse lendo mesmo, sabe, ela passa página por página, ela tem uma sequência" [La cuestión de concentración en actividades, lectura; tenemos el rincón de la lectura alli, una caja de libros, que a una determinada hora ella quiere; ella toma los libros, ella cuenta la historia de los libros, como si estuviera leyendo, sabes, pasa página por página, tiene una secuencia] (P4).

Las narrativas señalan que no hay continuidad en los ciclos de aprendizaje por factores externos como el cambio de ciudad, dejar de asistir al atendimiento especializado. En ocasiones son enseñados algunos contenidos, pero estos son olvidados, la profesora detecta que el niño reconoce letras, por ejemplo, pero presenta dificultades en la identificación de palabras.

"ele estava num ritmo muito bom, ele tava fazendo laboratório de... que a gente chama de AEE: atendimento ao aluno especial, entendeu? Ele fazia o AEE, ele estava na fono... eu peguei o B. assim. Ai houve uma quebra no início do ano passado quando ele foi morar no Rio e ano passado todo ele ficou sem atendimento" [Se encontraba a un ritmo muy bueno, estaba haciendo laboratorio de... cuando la gente llama de AEE: atención al alumno especial, ¿entendió? Él hacía el AEE, él estaba en la fono... tomé a $B$. En ese momento hubo una ruptura a principios del año pasado cuando fue a vivir en Río y todo el año pasado se quedó sin atención (P2).

"Ela, assim, nós estamos começando, assim as atividades com ela, o conteúdo assim de educação infantil, tá? está começando com as letras, com os números... então, com as vogais primeiro; então assim: as letras soltas ela sabe, mas se tiver assim, escrito assim: CASA, e você pedir 
pra ela colorir a letra C, ela não sabe" [Ella, asi, estamos empezando las actividades con ella, el contenido de educación infantil, ¡está? está empezando con las letras, con los números... con las vocales primero; entonces: ella sabe las letras sueltas, pero si tiene escrito CASA, y usted le pide que coloree la letra $C$, ella no sabe] (P3).

Sin embargo, algunas de las narraciones incluyen experiencias de progreso o desempeño satisfactorio en lo concerniente al reconocimiento de las letras.

"Ai essa semana eu descobri que ele tá pronto pra ser alfabetizado, entendeu? Porque ele já conhece todo o alfabeto, agora a gente já parte pro nivel silábico." [En esa semana descubri que él estaba listo para ser alfabetizado, entendió? Porque él ya conoce todo el alfabeto, ahora la gente ya parte a nivel silábico] (P1).

En lo que se refiere a características de comportamiento, son descritas conductas de timidez e introversión que, de acuerdo con las narrativas de las docentes, dificultan la aproximación y confianza en la relación pedagógica construida entre profesora-estudiante.

"eu acho a P. uma criança muito tímida, é... uma personalidade forte, pra você conquistar ela, você assim, demora bastante." [yo creo a P. un niño muy timido, tiene una personalidad fuerte, para que puedas conquistarla, tú asi, demora bastante] (P3).

Unido al aspecto comportamental se identifican estados de ánimo y emociones en la relación profesora-estudiante con DI. Las profesoras manifiestan que deben lidiar en ocasiones con comportamientos agresivos, sentimientos de rabia, entre otros. Sin embargo, varias de las narrativas señalan esto como temporal, resaltando que son observados avances actitudinales que favorecen procesos de aprendizaje.

"Então a gente não insiste muito não, que se não ela... acaba ficando nervosa, porque a T. é assim, meio malcriada às vezes, agressiva assim, com palavras. Então, mas esse ano ela já melhorou muito" [Entonces la gente no insiste mucho no, que si no ella... acaba quedando nerviosa, porque T. es asi, medio malcriada a veces, agresiva, con palabras. Pero ese año ella ha mejorado mucho] (P4). 
Los profesores mantienen unas expectativas frente al desempeño escolar del estudiante con SD. Estas incluyen dar continuidad al proceso de alfabetización, potencializar habilidades sociales, estimular, invertir, brindar apoyo a las familias con hijos con DI, así como planificar actividades que traten temas de la vida diaria, características que favorecen este tipo de capacidades en los niños.

"Olha, eu... eu tenho quase certeza que a T. ela vai conseguir ser alfabetizada, ela vai ser alfabetizada." [Mira, yo... estoy casi seguro de que T. va a conseguir ser alfabetizada, va a ser alfabetizada] (P4).

"Eu acho que ele tem futuro, assim... lógico, a gente não vai esperar que ele chegue lá na faculdade, mas, por que não?" [Creo que tiene futuro, ... lógico, la gente no va a esperar que llegue a la universidad, pero, ¿por qué no?] (P1)

"ah, eu queria que ela arrumasse um emprego, que ela, entendeu? Fosse util na sociedade, que ela se sentisse útil na sociedade, essa é a minha expectativa". [Ah, yo quisiera que ella consiga un trabajo, que ella, ¿entendió? Fuese útil en la sociedad, que ella se sintiera útil en la sociedad, esa es mi expectativa] (P3)

\section{Discusión}

El análisis comparativo entre las respuestas del checklist de madres y profesoras logró evaluar algunos aspectos de esta relación. Madres y profesoras presentan diferencias en cuanto a su percepción frente a la relación F-E. De acuerdo con este instrumento aplicado en las madres, la estructura relacional padres-profesores demuestra tener pocos índices de ocurrencia, es decir, un reducido número de interacciones, existiendo más vínculos entre padres-estudiantes en lo que atañe a las áreas académicas y no académicas. En contraposición, las profesoras consideran que existe acercamiento entre F-E, tanto en áreas académicas y no académicas, en la mayoría de las actividades ya sean: orientación, participación o evaluación. 
Sin embargo, fueron identificadas mediante el checklist percepciones semejantes en la relación F-E; madres y docentes indicaron que no existe contacto suficiente entre las estructuras padre-profesordirección-estudiante, situación que puede afectar la relación F-E y que puede incluso llegar a convertirse en obstáculo para la inclusión escolar del estudiante con SD. Esta relación debe ser fortalecida a partir de sus diferentes canales de comunicación y participación; F-E conforman un sistema donde cada uno de sus miembros aporta y realiza papeles específicos para tornar esta relación posible.

Conforme la literatura señala, acciones conjuntas traen beneficios para el desarrollo del estudiante (Luiz et al., 2008; Páez, 2015; Dessen $\&$ Polonia, 2014). Se trata de un gran desafío promover la alianza entre F-E en cualquiera de los niveles de enseñanza, posibilitando que los padres se sientan partícipes y responsables en el éxito del proyecto escolar de su hijo (Marcondes \& Sigolo, 2012; Marques, 1996; Resende $\&$ Silva, 2016). En el mismo sentido, estudios muestran la importancia de promover la relación F-E desde un nivel macro-sistémico, es decir, a partir de la legislación educacional brasilera. Aspecto que recientemente viene siendo discutido en Brasil (Resende \& Silva, 2016).

Los resultados muestran, para el caso de las familias participantes con hijos con SD, que han venido construyendo una relación F-E en la cual el interés principal es el proceso de aprendizaje de su hijo. Se presentan semejanzas en la perspectiva tanto de los progenitores como de las profesoras participantes en actividades de orientación. Esta categoría presentó mayor ocurrencia, por ejemplo, para las profesoras los procesos de orientación ocurren entre ellas y otros agentes de la escuela como padres, estudiantes y dirección existiendo intercambio de ideas entre ellos. La orientación también fue la categoría destacada en el estudio de Polonia (2005) para el caso de familias con estudiantes con desarrollo típico, sugiriendo que posteriores estudios vinculen muestras mayores de participantes con el fin de obtener resultados más consistentes acerca de la relación F-E bajo el marco de la inclusión.

La interacción F-E es establecida por estándares sugeridos por la escuela a partir de una jerarquía vertical. La relación construida entre 
F-E la mayoría de las veces se restringe a acciones emitidas por parte del profesor, donde las dimensiones que involucran la estructura profesor-padre-dirección-estudiante fueron poco señaladas, siendo un obstáculo para la promoción de la relación y consecuentemente para la inclusión del estudiante con SD (Sigolo, 2012). Aunque el checklist muestre claramente que la relación F-E se construye a partir de la categoría de orientación; la categoría de información en el caso de las respuestas de profesoras no registró ocurrencia de intercambio de informaciones entre Padres-profesoras.

Esto significa que las docentes señalaron que los padres no acostumbran a buscar información acerca del rendimiento académico de sus hijos, en contraposición con las respuestas de progenitores que marcan la ocurrencia de información en la estructura padres-profesores, indicando que buscan información acerca del rendimiento de sus hijos, especialmente con fines de acompañamiento en tareas. Estos hallazgos son similares a los encontrados por Marcondes y Sigolo (2012) quienes consideran que la relación F-E se restringe al apoyo que padres ofrecen a sus hijos en la ejecución de trabajos y tareas extraescolares, considerando la poca participación de padres en otro tipo de actividades, así como ahondar en la información por el rendimiento académico de sus hijos.

Se evidenció alianza y soporte en la estructura profesor-dirección, las profesoras perciben apoyo en categorías como orientación, participación y evaluación. Este tipo de apoyo contribuye directamente en la actividad docente. En la estructura profesor-estudiante, consideran que los estudiantes están involucrados en acciones de orientación e información. Sin embargo, los estudiantes se vinculan muy poco a procesos de evaluación, aspecto que también fue destacado en el estudio de Marcondes y Sigolo (2012).

Los progenitores consideraron importante la relación F-E de acuerdo con lo manifestado durante las entrevistas. En lo que atañe a las concepciones que progenitores tienen acerca del papel de la escuela fueron identificadas varias narrativas. La escuela es caracterizada como la principal responsable por el aprendizaje formal. No fueron identificadas narrativas que hicieran alusión a la escuela con enfoque inclusivo, 
principios de igualdad de derechos, estrategias adecuadas para la promoción del desarrollo del estudiante con SD. Se considera que el paradigma de la inclusión no se encuentra dentro de las perspectivas que los progenitores construyen frente al papel que la escuela cumple.

Sin embargo, otras categorías relatadas por los padres tales como transmisión de valores, socialización, aceptación social, resaltan un papel más amplio del proceso de escolarización, sin ser reducido al tipo de educación formal, es decir, al aprendizaje de contenidos organizados (Dessen \& Polonia, 2014; Picanço, 2012). La escuela también tiene como objetivo la formación de la persona para el ejercicio de la ciudadanía (Dessen \& Polonia, 2014; Picanço, 2012).

El desempeño escolar de los estudiantes con SD y los cambios ocurridos en este proceso predominan en las narrativas de los participantes, son enfatizadas dificultades y falta de continuidad en el aprendizaje, es decir, hay avances, pero al mismo tiempo se perciben retrocesos, según las profesoras. Los avances son percibidos en los aspectos de socialización y de comportamiento de los niños. Las profesoras exponen sus percepciones de la alfabetización y la continuidad de la escolarización como herramientas para que los estudiantes con DI o SD logren independencia, materializada en oficios o profesiones que a futuro puedan ejercer. La anterior idea se contrapone con otros estudios en los cuales los profesores se muestran escépticos a las posibilidades de escolarización y aprendizaje de estudiantes con DI (Briant \& Oliver, 2012; Gomes \& Souza, 2012; Rabelo, 2013; Silva, 2007). Es necesario continuar desarrollando investigaciones que indaguen sobre las concepciones de los profesores acerca de la inclusión puesto que tanto los valores como las creencias influyen en las prácticas diarias en el salón de clases.

En debates recientes en Brasil con respecto a la relación F-E se destaca la necesidad de fortalecer este vínculo con el fin de incrementar la participación de los padres en el proceso académico de sus hijos. Una de las conclusiones en este debate reporta que es posible fortalecer la relación F-E en la medida en que sean formuladas leyes sobre este tema (Resende \& Silva, 2016). Una legislación que oriente la relación F-E puede ser necesaria, pero es importante comprender las 
particularidades y perspectivas tanto de los contextos sociales como de los distintos agentes que hacen posible la relación F-E.

El tema no se reduce a lo identificado y expuesto en este estudio, se considera que aún hay mucho por investigar, se sugieren sean consideradas diferencias regionales y culturales del contexto brasilero, así como la posibilidad de replicar esta clase de estudios en otros territorios, teniendo en cuenta la multiculturalidad de cada nación. Las investigaciones en el tema deben considerar las características de familias con hijos con SD y su dinámica relacional. Es necesario continuar indagando por la relación F-E de estudiantes con SD y otras NEE mediante la construcción y adaptación de instrumentos de recolección de datos que se ajusten a las particularidades de cada contexto. Este último aspecto fue una limitación del presente estudio, debido a que el checklist empleado fue una herramienta adaptada para las escuelas de Brasilia y en el momento de la aplicación fueron percibidas leves diferencias con las escuelas de la ciudad del estado de Minas Gerais donde el presente estudio fue realizado.

En este estudio se ha considerado que la relación F-E posibilita la inclusión escolar; la dinámica de esta relación brindará información por el cómo estos procesos de inclusión escolar transcurren. El discurso de la diversidad en la escuela no solo es un asunto mediante el cual los estudiantes socializan, sino que debe tener la firme intención de desarrollar espacios de aprendizaje que beneficien a toda la comunidad estudiantil en igualdad de condiciones.

\section{Referencias}

Bardin, L. (2011). Análise de conteúdo. São Paulo: Ediçôes 70.

Briant, M. E. P. \& Oliver, F. C. (2012). Inclusão de crianças com deficiência na escola regular numa região do município de São Paulo: Conhecendo estratégias e açóes. Revista Brasileira de Educação Especial, 18, 141-154. https://doi.org/10.1590/ S1413-65382012000100010 
Christovam, A. C. C. \& Cia, F. (2016). Comportamentos de pais e professores para promoção da relação família e escola de pré-escolares incluídos. Revista Educação Especial, 29(54), 133-146. http://dx.doi.org/10.5902/1984686X13441

Dessen, M. A. \& Cerqueira-Silva, S. (2011). Desenvolvimento sistemas de categorias com dados de entrevistas. En L. Weber \& M. A. Dessen (Orgs.). Pesquisando a família: Instrumentos para coleta e análise de dados (pp.45-59). Curitiba: Juruá.

Dessen, M. A. \& Polonia, A. C. (2011). Checklist da rotina compartilhada e envolvimento entre família-escola: Versão para pais e professores. En L. Weber \& M. A. Dessen (Orgs.). Pesquisando a família: instrumentos para coleta e análise de dados (pp.189-202). Curitiba: Juruá.

Dessen, M. A. \& Polonia, A. C. (2014). As relaçôes entre família e escola: contribuiçóes para o processo educativo. En M. A. Dessen \& D. A. Maciel (Orgs.), A ciência do desenvolvimento humano: desafios para a psicologia e a educação (pp. 235-264). Curitiba: Juruá.

Dusi, P. (2012). The family-school relationships in Europe: A research review. CEPS Journal, 2, 13-33.

Garcia, R. M. C. (2013). Política de educação especial na perspectiva inclusiva e a formaçáo docente no Brasil. Revista Brasileira de Educação, 18(52), 101-239. https://doi.org/10.1590/ S1413-24782013000100007

Gomes, C. \& Souza, V. L. T. (2012). Psicologia e inclusão escolar: reflexôes sobre o processo de subjetivação de professores. Psicologia Ciência e Profissäo, 32(3), 588-603. https://doi.org/10.1590/ S1414-98932012000300006

Junges, L. A. S. (2015). A relação familia-escola sob a perspectiva do professor de ensino fundamental (Tesis de Doctorado). Instituto de Psicologia da Universidade Federal do Rio Grande do Sul, Porto Alegre, RS.

Luiz, F. M. R. \& Nascimento, L. C. (2012). Inclusão escolar de crianças com síndrome de Down: Experiências contadas pelas famílias. Revista Brasileira de Educação Especial, 18(1), 127-140. https://doi.org/10.1590/S1413-65382012000100009 
Luiz, F. M. R., Bortoli, P. S., Floria-Santos, M. \& Nascimento, L. C. (2008). A inclusão da criança com síndrome de Down na rede regular de ensino: Desafios e possibilidades. Revista Brasileira de Educação Especial, 14, 497-508. ttps://doi.org/10.1590/ S1413-65382008000300011

Llevot, N. \& Bernad, O. (2015). La participación de las familias en la escuela: factores clave. RASE: Revista de la Asociación de Sociología de la Educación, 8(1), 57-70.

Marcondes, K. H. B. \& Sigolo, S. R. R. (2012). Comunicação e envolvimento: Possibilidades de interconexôes entre famíliaescola? Paidéia, 22(51), 91-99. https://doi.org/10.1590/ S0103-863X2012000100011

Marques, R. (1996). O envolvimento das famílias no processo educativo: Resultados de um estudo em cinco países. En $1^{\circ}$ Congreso Educação Hoje. Congreso celebrado en la Universidad de Lisboa, Lisboa.

Oliveira, C. B. E. \& Marinho-Araújo, C. M. (2010). A relação famíliaescola: Intersecçóes e desafios. Estudos de Psicologia, 27, 99-108. https://doi.org/10.1590/S0103-166X2010000100012

Páez, M. R. M. (2015). Familia y escuela una alianza necesaria en la gestión escolar. Revista Iberoamericana de Educación, 67, 159-180.

Pereira-Silva, N. L., Oliveira, D. L. \& Rooke, I. M. (2015). Familias con adolescentes con síndrome de Down: apoyo social y recursos familiares. Avances en Psicología Latinoamericana, 33(2), $267-$ 281. https://doi.org/10.12804/apl33.02.2015.07

Petrucci, G. W., Borsa, J. C. \& Koller, S. H. (2016). A família e a escola no desenvolvimento socioemocional na Infância. Temas em Psicologia, 24(2), 391-402. https://doi.org/10.9788/TP2016.2-01Pt

Picanço, A. L. B. (2012). A relação entre escola e familia - as suas implicaçóes no processo de ensino-aprendizagem (Disertación de Maestría). Escola Superior de Educação João de Deus, Lisboa, Portugal. 
Polonia, A. C. (2005). As relaçóes escola-familia: O que diretores, professores, pais e alunos pensam? (Tesis de Doctorado). Instituto de Psicologia da Universidade de Brasília, Brasília, D.F.

Powel, D. R., Son, S. H., File, N. \& San Juan, R. R. (2010). Parentschool relationships and children's academic and social outcomes in public school pre-kindergarten. Journal of School Psychology, 48, 269-292. https://doi.org/10.1016/j.jsp.2010.03.002

Pletsch, M. D. \& Glat, R. (2012). A escolarização de alunos com deficiência intelectual: uma análise da aplicação do Plano de Desenvolvimento Educacional Individualizado. Linhas Críticas, 18(35), 193-208.

Prata, M. (2009). O estudo das ideias e das práticas dos professores do $1^{\circ}$ ciclo do ensino básico acerca da inclusão educativa de crianças com necessidades educativas especiais (Tesis de Doctorado). Faculdade de Psicologia e de Ciências da Educação, Universidade do Porto, Lisboa, Portugal.

Rabelo, V. C. S. (2013). Inclusão escolar de alunos com sindrome de Down, familias e professoras: Uma análise bioecológica (Disertación de Maestria). Instituto de Ciências Humanas da Universidade Federal de Juiz de Fora, Juiz de Fora, MG.

Resende, T. F. \& Silva, G. F. (2016). A relação família-escola na legislação educacional brasileira (1988-2014). Ensaio: Avaliação e Políticas públicas em Educação, 24(90), 30-58. http://dx.doi. org/10.1590/S0104-40362016000100002.

Sánchez E, P. \& Valdés C, Á. (2011). Una aproximación a la relación entre el rendimiento académico y la dinámica y estructura familiar en estudiantes de primaria. Revista Intercontinental de Psicología y educación, 13(2), 177-196.

Saraiva, L. A. \& Wagner, A. (2013). A relação família-escola sob a ótica de professores y pais de crianças que frequentam o ensino fundamental. Ensaio: Avaliação e Políticas públicas em Educação, 21(81), 739-772. https://doi.org/10.1590/ S0104-40362013000400006 
Sigolo, S. R. R. (2012). A colaboração da família nos processos educacionais de crianças com deficiência: Pontos para reflexão. In L. E. Melchiori, O. M. P. Rodrigues \& A. C. B. Maia (Orgs.). Familia e crianças: Reflexóes teórico-práticas sobre os cuidados com as crianças (pp.153-164). Curitiba: Juruá.

Silva, K. F. W. (2007). Inclusão escolar de alunos com deficiência mental: Possiveis causas de insucesso (Disertación de Maestría). Instituto de Psicologia da Universidade Federal do Rio Grande do Sul, Porto Alegre, RS.

Silva, A. M. \& Mendes, E. G. (2008). Família de crianças com deficiência e profissionais: Componentes da parceria colaborativa na escola. Revista Brasileira de Educação Especial, 14, 217-234. https://doi.org/10.1590/S1413-65382008000200006

Sousa, M. M. \& Pereira, M. T. J. (2014). A percepçáo de encarregados de educação e de professores sobre a relação escola-família nas escolas dos $2^{\circ}$ e $3^{\circ}$ ciclos de um Concelho da regiáo centro de Portugal. Revista Eletrônica de Educação, 8(2), 321-344. http:// dx.doi.org/10.14244/19827199785

Varani, A. \& Silva, D. C. (2010). A relação família-escola: Implicaçóes no desempenho escolar dos alunos dos anos iniciais do ensino fundamental. Revista Brasileira de Estudos Pedagógicos, 91(229), 511-527.

Whitaker, D., Graham, C., Severtson, S. G., Furr-Holden, C. D. \& Latimer, W. (2012). Neighborhood \& Family effects on learning motivation among urban African American middle school youth. Journal of Child Family Studies, 21, 131-138. https://doi. org/10.1007/s10826-011-9456-1

Zanato, C. B. \& Gimenez, R. (2017). Educação Inclusiva: um olhar sobre as adaptaçóes curriculares. Revista @mbienteeducação, 10(2), 289-303. https://doi.org/10.26843/ ae19828632v10n22017p289a303

Recibido: 30 de setiembre, 2016

Revisado: 11 de setiembre, 2017 Aceptado: 31 de enero, 2018 